\title{
Evaluation of the Quasi-Biweekly Oscillation over the South China Sea in Early and Late Summer in CAM5
}

\author{
XU WANG \\ Ministry of Education Key Laboratory for Earth System Modeling, Department of Earth System Science, Tsinghua University, \\ and Joint Center for Global Change Studies, Beijing, China \\ GUANG J. ZHANG \\ Scripps Institution of Oceanography, La Jolla, California, and Ministry of Education Key Laboratory for Earth System Modeling, \\ Department of Earth System Science, Tsinghua University, Beijing, China
}

(Manuscript received 10 February 2018, in final form 1 October 2018)

\begin{abstract}
Low-frequency intraseasonal oscillations in the tropical atmosphere in general circulation models (GCMs) were studied extensively in many previous studies. However, the simulation of the quasi-biweekly oscillation (QBWO), which is an important component of the intraseasonal oscillations, in GCMs has not received much attention. This paper evaluates the QBWO features over the South China Sea in early [May-June (MJ)] and late [August-September (AS)] summer in the National Center for Atmospheric Research (NCAR) Community Atmosphere Model, version 5.3 (CAM5), using observations and reanalysis data. Results show that the major features of the spatial distribution of the QBWO in both MJ and AS are simulated reasonably well by the model, although the amplitude of the variation is overestimated. CAM5 captures the local oscillation in MJ and the westward propagation in AS of the QBWO. Although there are important biases in geographical location and intensity in MJ, the model represents the QBWO horizontal and vertical structure qualitatively well in AS. The diagnosis of the eddy vorticity budget is conducted to better understand the QBWO activities in the model. Both horizontal advection of relative vorticity and that of planetary vorticity (Coriolis parameter) are important for the local evolution of the QBWO in MJ in observations as well as model simulation, whereas advection of planetary vorticity contributes to the westward propagation of QBWO vorticity anomalies in AS. Since the Coriolis parameter $f$ only changes with latitude, this suggests that the correct simulation of anomalous meridional wind is a key factor in the realistic simulation of the QBWO in the model.
\end{abstract}

\section{Introduction}

The quasi-biweekly oscillation (QBWO), defined as a 1020-day oscillation, is a high-frequency component of tropical variation, whose time scale is between the scales of synoptic and the Madden-Julian oscillation (MJO; Madden and Julian 1971, 1972). It is closely connected to tropical and subtropical weather and seasonal mean climate. A number of previous studies investigated the QBWO associated with the Asian monsoon. Keshavamurty (1972) found the QBWO in the lower-tropospheric meridional wind field of the Indian summer monsoon. The westward-propagating feature of the QBWO in the Indian monsoon was revealed by Murakami and Frydrych (1974), Krishnamurti and Bhalme (1976), and Krishnamurti and Ardanuy (1980).

Corresponding author: Guang J. Zhang, gzhang@ucsd.edu
Murakami (1976) pointed out that the QBWO has a close relationship with the active/suppressed cycle of the Indian summer monsoon. Many earlier investigations also showed that the QBWO exists in the South China Sea (SCS) monsoon and influences the monsoon onset and break (e.g., Chen and Chen 1995; Chen et al. 2000; Chan et al. 2002; Mao and Chan 2005). Wang et al. (2009) and Kikuchi and Wang (2009) showed that the QBWO over the SCS is very active in summer, even more active than that in the Indian summer monsoon.

The connection between the QBWO and tropical cyclone (TC) and rainfall was also studied. Liang et al. (2011) and Wu et al. (2011) reported the impact of the QBWO on the TC track and showed that a TC originally moving westward turned northward as it encountered a QBWO. Mao and Wu (2006) noted that the active and break periods of rainfall over the middle and lower 
range of the Yangtze River basin were mainly regulated by a QBWO during the 1991 summer. Yang et al. (2010) and Liu et al. (2014) also found close relationships between the QBWO and rainfall in the Yangtze and Huai River basin of China in summer. Li et al. (2015) found that there was high positive correlation between the summer (May-October) precipitation anomaly and the intensity of the QBWO, resulting from the favorable large-scale environmental conditions.

Recently, attention has also been paid to the intraseasonal features of the QBWO. Fukutomi and Yasunari (1999) explored the linkage between tropical convection and subtropical lower-tropospheric circulation on the QBWO scale during early summer (June-July), and found that convection on the QBWO time scale in the SCS was closely connected to the atmospheric circulation in the whole Asian-Pacific region. They suggested that the variability of monsoon convection and circulation over East Asia (EA) and the western North Pacific (WNP) were closely related to the interaction between the tropics and the subtropics on the QBWO scale. Li and Wang (2005) showed large differences between the early [May-July (MJJ)] and late [August-October (ASO)] summer QBWO in its spatial distribution of variance. The major center of QBWO variance was located over the SCS in MJJ, but extended eastward to the east of the Philippines in ASO. Chen and Sui (2010) examined the QBWO over the WNP during late summer (July-October) and found that it exhibited a southeast-northwest wave train pattern with about $3500-\mathrm{km}$ wavelength. This indicates that the QBWO origin is related to an equatorial Rossby wave. Jia and Yang (2013) investigated the impact of the QBWO over the WNP on the EA summer monsoon during early summer. Their analysis showed that the QBWO had a considerable influence on the subtropical EA rainfall. As the convective QBWO propagates northwestward from the tropical western Pacific to the SCS, the rainfall anomalies showed systematic and substantial changes in both tropical and subtropical EA. Xu et al. (2017) found the intensity of the QBWO over the WNP was weakened during late summer (August-November) after the late 1990s and suggested that surface moisture change played an important role in the weakening. Comparing the QBWO in different summer stages, Yang et al. (2014) found that the spatial distributions and propagation paths of the QBWO over the EA were very different in early (10 June-20 July) and late (21 July31 August) summer. Wang et al. (2016), Chen and Wang (2017), and Wang and Chen (2017) also found distinctly different characteristics of the QBWO in early [MayJune (MJ)] and late [August-September (AS)] summer over the SCS. They showed that the QBWO exhibits a local standing oscillation over the SCS in MJ, but propagates northwestward from the east of the Philippines to the SCS in AS. Through vorticity budget analysis, they proposed that the evolution of the QBWO is closely associated with the meridional wind anomalies in the large-scale circulation.

A number of studies (Kang et al. 2002; Waliser et al. 2003; Lin et al. 2008; Sabeerali et al. 2013) have examined the simulation of low-frequency tropical intraseasonal variability and its role in the summer monsoon in general circulation models (GCMs). The QBWO is at the highfrequency end of the intraseasonal time scale $(\mathrm{Li}$ and Zhou 2013). Considering the significance of the QBWO in Asian summer monsoon, a proper simulation of this variability in the state-of-the-art GCMs is of great importance. As Ko and Vincent $(1995,1996)$ suggested, investigation of this shorter intraseasonal mode could provide useful information to extended-range weather forecasting. However, few studies have investigated the simulation of the QBWO in GCMs. Hu et al. (2017) examined the QBWO in the WNP during summer (MayOctober) in 12 coupled GCMs participating in the Intergovernmental Panel on Climate Change (IPCC) Fifth Assessment Report (AR5) and showed that in general the models successfully captured the westward propagation of the QBWO. Are the significant subseasonal variability in variance and propagation features in summer properly simulated in GCMs? With this question in mind, we evaluate the simulation of the QBWO in early (MJ) and late (AS) boreal summer using the Community Atmosphere Model, version 5.3 (CAM5), in this study.

The paper is organized as follows. Section 2 describes the model, data, and methodology used in this study. In section 3, the simulation results of the variance, power spectrum, propagation, and structure features associated with the QBWO are compared with the observations to evaluate the QBWO activities in CAM5. In section 4, the eddy vorticity budget associated with the QBWO in the model is further analyzed to better understand the simulation results of the QBWO shown in section 3. Finally, the conclusions are given in section 5 .

\section{Model, evaluation data, and methodology}

The model examined in this study is the National Center for Atmospheric Research (NCAR) CAM5 (Neale et al. 2012), which is the atmospheric component of the Community Earth System Model, version 1.2 (CESM1.2). The deep convection scheme is the ZhangMcFarlane scheme (Zhang and McFarlane 1995), with modifications to the closure using dilute convective available potential energy (CAPE) by Neale et al. (2008). Other relevant physical parameterizations in CAM5 include a boundary layer moist turbulence 
scheme by Bretherton and Park (2009), a shallow convection scheme by Park and Bretherton (2009), a twomoment cloud microphysics scheme for stratiform clouds by Morrison and Gettelman (2008), and a radiation scheme, which employs an efficient and accurate correlated- $k$ method for calculating radiative fluxes and heating rates (Mlawer et al. 1997; Iacono et al. 2000).

CAM5 with a finite volume dynamic core at a resolution of $1.9^{\circ} \times 2.5^{\circ}$ in the horizontal and 30 levels in the vertical is used in this study. An AMIP-style simulation is conducted with monthly observed sea surface temperature (SST), sea ice, and external radiative forcing starting from 1984. Daily output from 20 years (19852004) from this AMIP simulation are analyzed. The daily National Centers for Environmental PredictionDepartment of Energy (NCEP-DOE) Reanalysis-2 (NCEP-2) dataset (Kanamitsu et al. 2002) and daily outgoing longwave radiation (OLR) data from the National Oceanic and Atmospheric Administration (NOAA) satellite (Liebmann 1996) are used for model evaluation. Both the reanalyses and observational data are interpolated from $2.5^{\circ} \times 2.5^{\circ}$ to $1.9^{\circ} \times 2.5^{\circ}$ horizontal resolution, and the model data are interpolated to 12 pressure levels $(1000,925,850,700,600,500,400,300$, $250,200,150$, and $100 \mathrm{hPa}$ ) in the vertical to match the vertical resolution in the reanalyses data.

The Lanczos filter (Duchon 1979) is applied to extract the 10-20-day signals. Before filtering, the 20-yr (19852004) linear trend and annual cycle are removed from the time series. To examine the propagation and spatial structure of the QBWO, a multiyear composite of the QBWO is performed using both observations and CAM5-simulation output for 1985-2004. The composite QBWO cycle is divided into nine phases. Phase 1 is the initiation phase of the active QBWO. Phase 3 corresponds to the mature stage. Phase 5 is the transition from active to inactive phase. Phase 7 represents the most inactive QBWO stage, and phase 9 is the end of the QBWO cycle. Phases 2, 4, 6, and 8 are intermediate phases between phases $1,3,5,7$, and 9 . The whole cycle lasts for about 10-20 days in time. A case is selected if the normalized anomalies at phases 3 and 7 are beyond one standard deviation of the OLR time series over the SCS. In observations (CAM5), 50 (33) and 51 (37) cases are identified in MJ and AS from 1985 to 2004, respectively. In each phase, besides the basic fields such as OLR, winds, vorticity, and divergence, the diabatic heating (apparent heat source) anomalies associated with convection are computed as the residual of the temperature equation,

$$
Q_{1}=c_{p} \frac{\partial T}{\partial t}-c_{p}\left(\omega \sigma-\mathbf{V}_{h} \cdot \nabla T\right)
$$

where $c_{p}$ denotes the specific heat at constant pressure, $T$ is the air temperature, $t$ is time, $\omega$ is the vertical velocity, $\sigma=\left(R T / c_{p} p\right)-(\partial T / \partial p)$ represents the static stability, $R$ is the gas constant, $p$ is the pressure, $\mathbf{V}_{h}$ is the horizontal velocity vector, and $\nabla_{h}=(\partial / \partial x)+(\partial / \partial y)$ is the horizontal gradient operator. In addition, the analysis of eddy vorticity budget on a 10-20-day time scale is conducted to examine the propagation dynamics of the QBWO in the model.

\section{Results}

\section{a. Variance and power spectrum}

To examine the spatial distribution and intensity of the QBWO in early (MJ) and late (AS) summer, we present the variance and power spectrum first. In observational studies, Li and Wang (2005) and Wang et al. (2016) showed that there existed large differences in the distribution and intensity of QBWO variance between early and late summer. Figure 1 shows the 10-20-day variance of OLR from observations and the CAM5 simulation. Significant variance is mainly concentrated in the SCS in MJ (Fig. 1a), in agreement with previous observational studies (e.g., Fukutomi and Yasunari 1999; Li and Wang 2005; Jia and Yang 2013). This is successfully simulated in CAM5 (Fig. 1d). However, the magnitude of the variance is much larger in the model than in observations, indicating that CAM5 overestimates the QBWO signal. Comparing with MJ (Fig. 1a), the observed variances to the east of the SCS are enhanced in AS (Fig. 1b). The large variance extends eastward to about $170^{\circ} \mathrm{E}$ along $20^{\circ} \mathrm{N}$ and forms a distinct elongated belt (Fig. 1c), consistent with that in Li and Wang (2005) and Wang et al. (2016). For the CAM5 simulation (Fig. 1f), an enhancement also occurs east of the SCS from MJ to AS, albeit with a much broader areal coverage. The northward shift of the center of variance in both the SCS and the western Pacific, as reflected by the weakening south of $10^{\circ}-15^{\circ} \mathrm{N}$ and strengthening north of $10^{\circ}-15^{\circ} \mathrm{N}$, is also qualitatively captured in the model. Overall, the major features of the QBWO variance in MJ and AS are well simulated by CAM5, but the model overestimates the amplitude of the variance.

Figure 2 shows the power spectrum of OLR from observations and the CAM5 simulation. The observed OLR has a statistically significant (exceeding 95\% confidence level) power peak in the 10-20-day period over the SCS in both MJ and AS (Figs. 2a,b), with the peak in MJ (Fig. 2a) at a longer time period (about 15 days) than in AS (Fig. 2b; about 12 days). For the CAM5 simulation, there is a stronger peak in the QBWO period in MJ (Fig. 2c) but with a shorter period (about 13 days) than that in observations (Fig. 2a). As for AS (Fig. 2d), the spectral power in the 10-20-day 

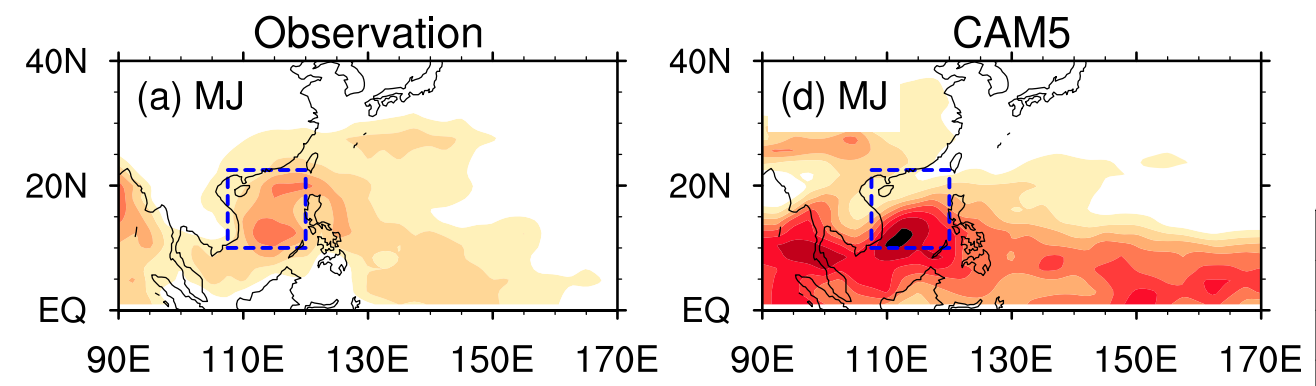

500

450

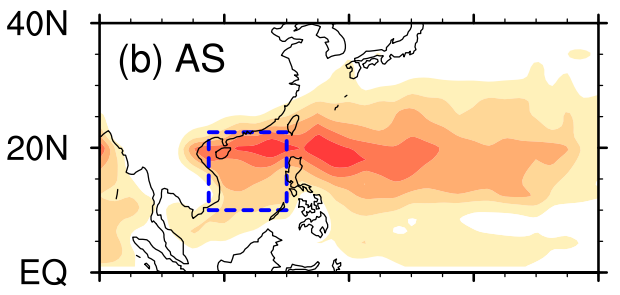

$40 \mathrm{~N}$

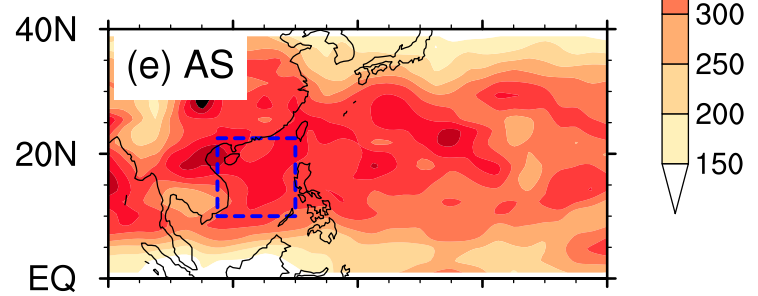

90E 110E 130E 150E 170E 90E 110E 130E 150E 170E
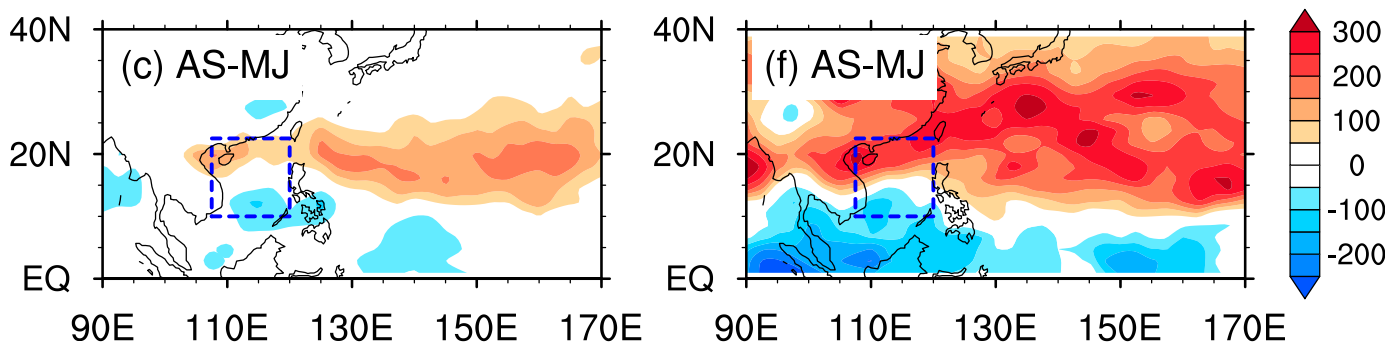

FIG. 1. Geographical distributions of 10-20-day OLR variance in (left) observations and (right) the CAM5 simulation for (a),(d) MJ; (b),(e) AS; and (c),(f) their differences. The shading interval is $50 \mathrm{~W} \mathrm{~m}^{-2}$. The SCS, defined as the region of $10^{\circ}-22.5^{\circ} \mathrm{N}, 107.5^{\circ}-120^{\circ} \mathrm{E}$, is outlined by the blue-dashed rectangle in each plot.

time period does not pass the $95 \%$ confidence level except for the peak near the 10-day period. In short, the signal of the simulated QBWO is significant enough over the SCS in MJ, although the period is shorter than that in observation. In contrast, the QBWO signal in AS is weak in the model. In Hu et al. (2017), two significant spectral peaks around 11 and 15 days were also found in the Global Precipitation Climatology Project (GPCP) unfiltered precipitation over WNP $\left(10^{\circ}-20^{\circ} \mathrm{N}, 120^{\circ}-\right.$ $170^{\circ} \mathrm{E}$ ) during boreal summer (May-October), consistent with the two OLR peaks shown in MJ and AS. Comparing with the GPCP observations, they showed a shorter period (about 13 days) but with more significant signal than the observed 15-day peak in the CCSM4 model, similar to that in MJ in CAM5 here. As for the 11-day peak, the signal was weaker in CCSM4, as in the AS result in CAM5.

\section{b. Propagation of the $Q B W O$}

Next, results of the QBWO propagation are presented for evaluating the QBWO activities. Figure 3 shows the evolution of the composite QBWO from observations and the CAM5 simulation for MJ. Because the pattern at phase 9 is very similar to that at the initial phase (phase 1), only phases 1-8 are shown. At the initial phase (Fig. 3a), there are no discernible convective anomalies in the SCS. By phase 2 (Fig. 3b), a center of positive convective anomalies (negative OLR anomalies) has established in the SCS, implying the development of the active phase of the QBWO. The positive convective anomalies in the SCS reach the maximum at the mature phase (Fig. 3c) and decrease gradually afterward. By phase 4 (Fig. 3d), the anomalies are much weaker. Phases 5-8 (Figs. 3e-h) describe the opposite half, the suppressed convection phases, of the QBWO cycle. Overall, the observed QBWO exhibits a standing oscillation in the SCS in MJ, as found in Wang et al. (2016) and Chen and Wang (2017). In contrast, a clear westward-propagation feature for the QBWO in early summer (June-July) was shown in Fukutomi and Yasunari (1999) and Jia and Yang (2013). It is likely this westward propagation mainly comes from QBWO signals in July, 

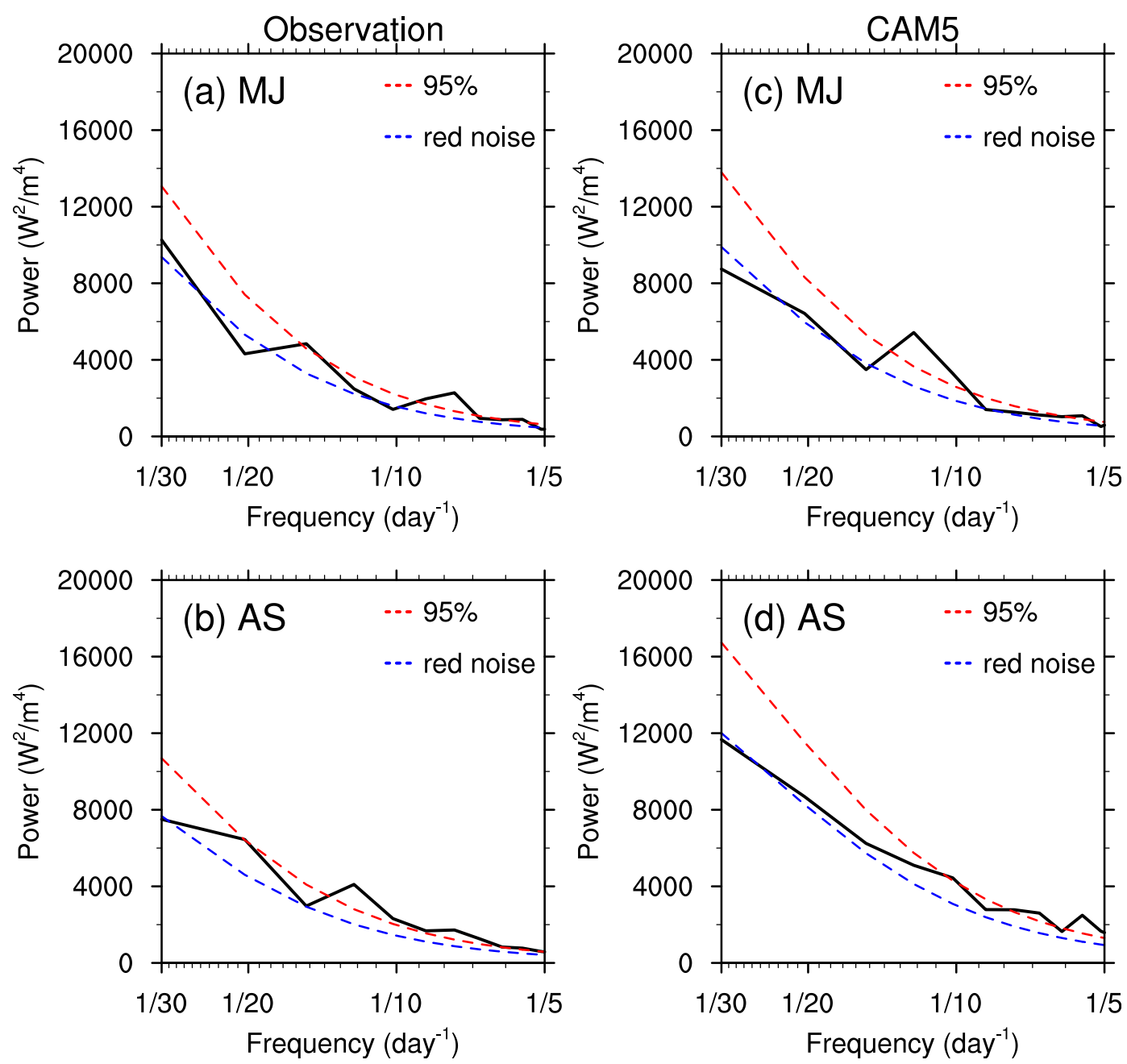

FIG. 2. Ensemble power spectra of observed OLR (black solid line) in (a) MJ and (b) AS averaged in the SCS. (c),(d) As in (a) and (b), but for the CAM5 simulation. The red noise spectrum (blue dashed line) and $95 \%$ confidence level (red dashed line) are also shown in each plot.

which is a transition time between early and late summer, as suggested by Kemball-Cook and Wang (2001). The CAM5 simulation (Figs. 3i-p) captures the local oscillation very well in its geographical location as well as the phases. However, the anomaly intensity in the model is larger than observed. In addition, the convection signal extends northwestward from the SCS to the Tibetan Plateau in phases 2 and 3 in the model, in disagreement with observations.

Figure 4 shows the evolution of the QBWO from phase 1 to 8 for AS. In the initial phase (Fig. 4a), weak convective anomalies appear over the central and northern part of the Philippines and to its east. By phase 2 (Fig. 4b), the area of convective anomalies has expanded westward to the SCS. At phase 3 (Fig. 4c), the convective anomalies move farther westward and slightly northward to the SCS, reaching a maximum in intensity. Afterward (at phase 4), the anomalies weaken gradually, oriented northeast to southwest from the SCS to the Indochina Peninsula with the center in the western SCS (Fig. 4d). The convective anomalies over the SCS and the Indochina Peninsula have almost disappeared at phase 5 (Fig. 4e), while weak negative convective anomalies start to develop east of the Philippines. From phase 5 to 8 (Figs. $4 \mathrm{e}-\mathrm{h}$ ), the convective anomalies undergo the suppressed phases of the QBWO cycle. Different from the standing oscillation in MJ, the evolution in AS exhibits a distinct westward propagation from east of the Philippines to the western SCS, resembling the propagating feature of the QBWO in WNP (Mao and Chan 2005; Kikuchi and Wang 2009; Chen and Sui 2010). In addition, the southwest-northeast elongated horizontal structure in the mature stage (Fig. 4c) is also similar to that shown in WNP (Chen and Sui 2010). 

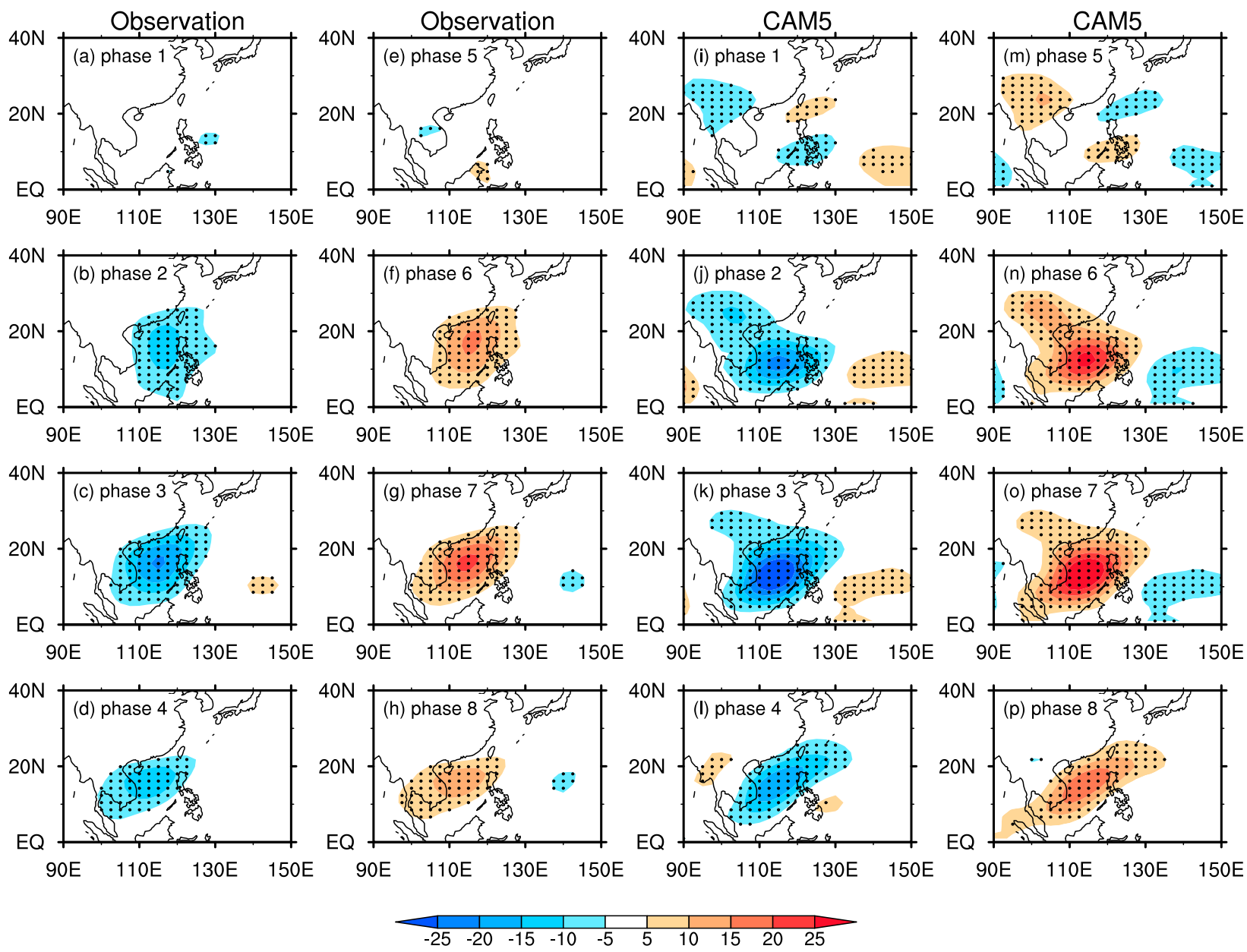

FIG. 3. Evolution of composite 10-20-day (a)-(h) observed and (i)-(p) CAM5-simulated OLR anomalies (W $\mathrm{m}^{-2}$ ) in MJ. Regions passing the $99 \%$ significance level $t$ test are stippled.

Chatterjee and Goswami (2004), Kikuchi and Wang (2009), and Chen and Sui (2010) suggested that this westward-propagating QBWO is associated with equatorial Rossby waves driven by convective coupling with planetary boundary layer convergence (Wang 1988; Wang and Li 1994). The CAM5 simulation (Figs. 4i-p) shows a similar spatial pattern and propagation features of convective anomalies in AS. The convective anomalies emerge initially to the east of the Philippines, move westward to the SCS, and reach the maximum at phase 3 with the center in the SCS before weakening as they propagate farther westward into the Indochina Peninsula. Nevertheless, there are clear differences between the model simulation and observations. First, the spatial scale is much broader in the simulated QBWO. Second, the intensity of the anomalies is too strong compared with observations.

To examine the propagation features of the QBWO in MJ and AS more closely, Fig. 5 shows the longitudephase Hovmöller plot of OLR from observations and the CAM5 simulation. From Figs. 5a and 5b, significant convective anomalies are mainly concentrated between $107.5^{\circ}$ and $120^{\circ} \mathrm{E}$ in $\mathrm{MJ}$ in both observations and the model simulation, with no propagation. On the other hand, in AS (Figs. 5c,d) the QBWO propagates westward distinctly in both observations and the model, similar to results shown in Hu et al. (2017). The observed convective anomalies start from $140^{\circ} \mathrm{E}$, move westward to the SCS and end at $100^{\circ} \mathrm{E}$. For CAM5, it shows a similar propagation speed for the QBWO, but with much stronger intensity. However, it extends too far westward to the Indochina Peninsula and the eastern Indian Ocean $\left(90^{\circ} \mathrm{E}\right.$ and beyond).

Overall, the model has a good simulation of the activities of the QBWO in both MJ and AS, especially in the spatial pattern and propagation. The overestimation in intensity of the convective anomalies is a main bias in the model, same as that in the simulated variance presented in Fig. 1. The QBWO in AS also extends too far 

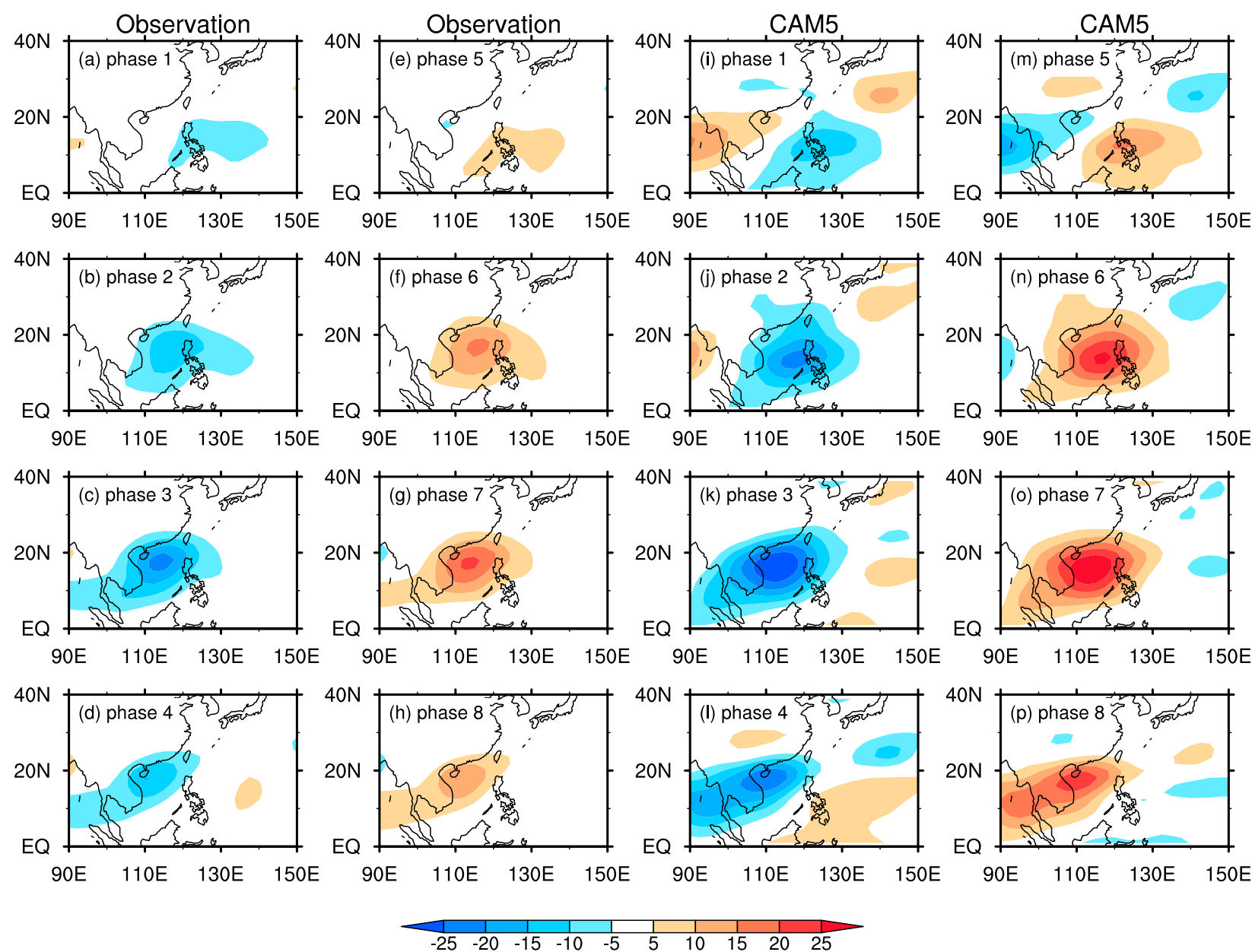

FIG. 4. As in Fig. 3, but for AS.

westward in the CAM5 model compared to observations. However, by tracking individual QBWO convection events using 20 years of OLR data Kikuchi and Wang (2009) showed that some QBWO events do travel farther westward and dissipate in the Indian Ocean.

\section{c. Spatial structure}

The spatial structure of the circulation and other dynamic fields associated with the QBWO at its mature phase is examined next. It is well known that low-level cyclonic (anticyclonic) circulation and convergence (divergence) can enhance (suppress) convective development. From Figs. $6 \mathrm{a}$ and $6 \mathrm{~b}$, in observations significant low-level $(925 \mathrm{hPa})$ cyclonic circulation and convergence anomalies are collocated in the SCS at phase 3 in both MJ and AS. These anomalies promote the strengthening of convection, benefiting the QBWO development. In CAM5, the lowlevel convergence anomalies are well simulated in both MJ and AS (Figs. 6c,d). However, the model apparently underestimates the anomalous convergence intensity in $\mathrm{MJ}$
(Fig. 6c), which is inconsistent with the OLR anomalies (as a proxy for convection) in Figs. 3 and 5. A further examination of the vertical distribution of mass convergence (not shown) finds that in CAM5 there is a deep layer of convergence in the lower to midtroposphere, leading to strong upward motion in the upper troposphere (near $300 \mathrm{hPa}$ ), whereas in observations convergence is mostly concentrated below $850 \mathrm{hPa}$ (also see Fig. 7 below). Same as for the OLR anomalies (Figs. 3c,k), the low-level convergence center in CAM5 is located a few degrees to the south of that in observations, coinciding with the QBWO convection center. The cyclonic circulation (or vorticity) center does not coincide with the convergence center, but rather is shifted southwestward to the south of the Indochina Peninsula. It is not clear to us what led to the separation of the vorticity center from the convergence center. We suspect that it may in part be related to the anticyclonic mean circulation in the model in SCS (see Fig. 10 below). Nevertheless, the QBWO convection is still located in the generally cyclonic circulation region. As for AS (Fig. 6d), 
(a) MJ Obesrvation

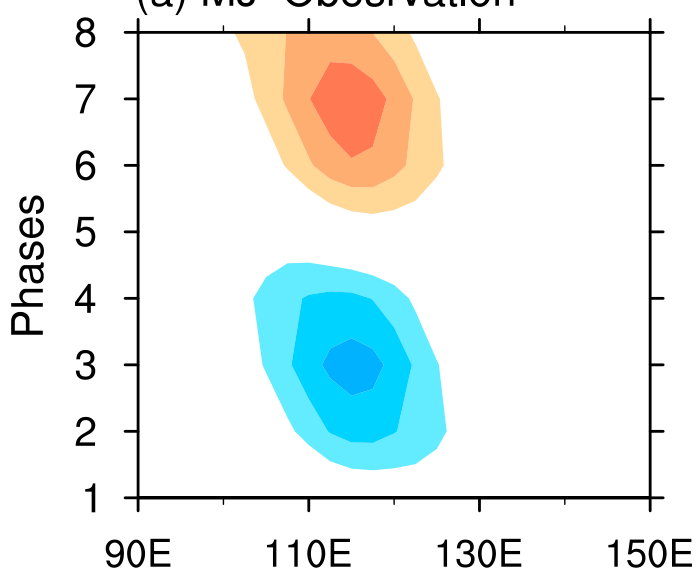

(b) MJ CAM5

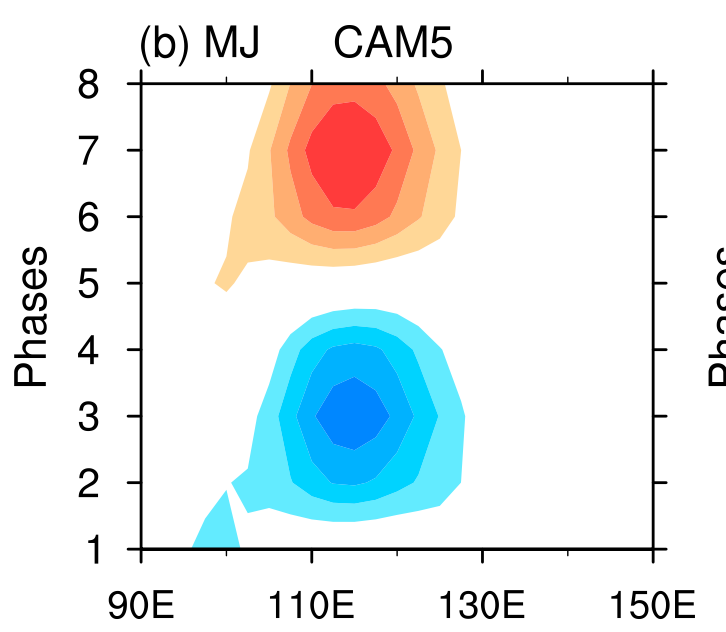

(c) AS Observation

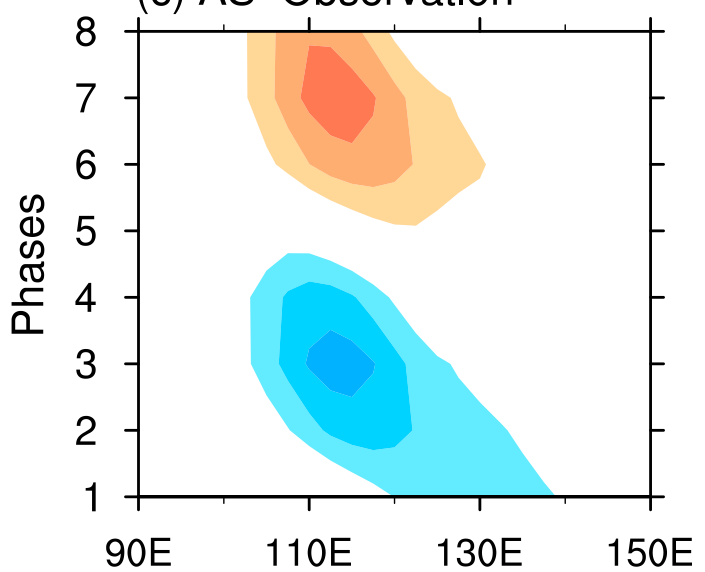

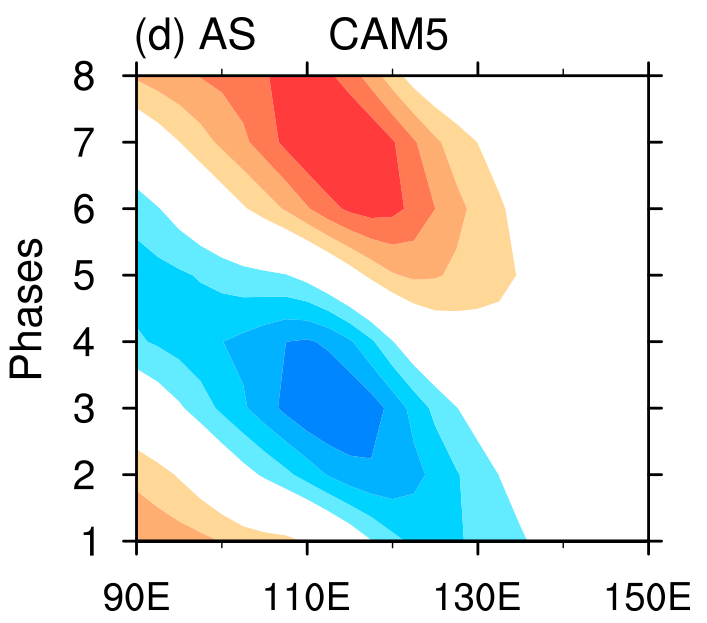

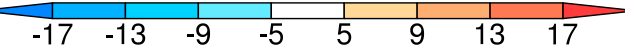

FIG. 5. The longitude-phase Hovmöller plots of composite 10-20-day (a) observed and (b) simulated OLR, averaged from $10^{\circ}$ to $22.5^{\circ} \mathrm{N}$ in MJ. (c), (d) As in (a) and (b), but in AS. The shading interval is $4 \mathrm{~W} \mathrm{~m}^{-2}$, starting from $\pm 5 \mathrm{~W} \mathrm{~m}^{-2}$.

the cyclonic circulation and convergence anomalies are simulated well by the model in terms of both location and intensity.

Figure 7 shows the height-longitude cross sections of anomalous vorticity, vertical velocity, and the apparent heat source. In observations (Figs. 7a,c), positive relative vorticity anomalies extend from the surface to about $300 \mathrm{hPa}$ in the SCS in both MJ and AS at phase 3, with negative anomalies above. This is similar to that of the summer intraseasonal oscillation in ERA-Interim $(\mathrm{Hu}$ et al. 2017). The pronounced low-level positive vorticity anomalies provide a favorable condition for the QBWO development. In the CAM5 simulation, the intensity of the low-level positive vorticity anomalies is extremely underestimated in MJ (Fig. 7b), while the intensity of the upper-level negative vorticity anomalies is slightly overestimated. The vertically tilted and longitudinally shifted maximum and minimum centers differ greatly from the observed structure, with the negative vorticity anomalies east of the positive anomalies much more pronounced in the model throughout the troposphere than in observations. Further examination of the vorticity distribution in the upper troposphere (not shown) finds that the westward tilt of positive vorticity anomalies above $500 \mathrm{hPa}$ in CAM5 is largely due to contributions from a large positive vorticity center north $20^{\circ} \mathrm{N}$ south of the Tibetan Plateau, which is much weaker in observations. Also, recall that (Fig. 6c) the vorticity center is displaced to the southwest of the center of the QBWO convection anomalies, thus the vorticity anomalies in Fig. $7 \mathrm{~b}$ are likely affected by this 

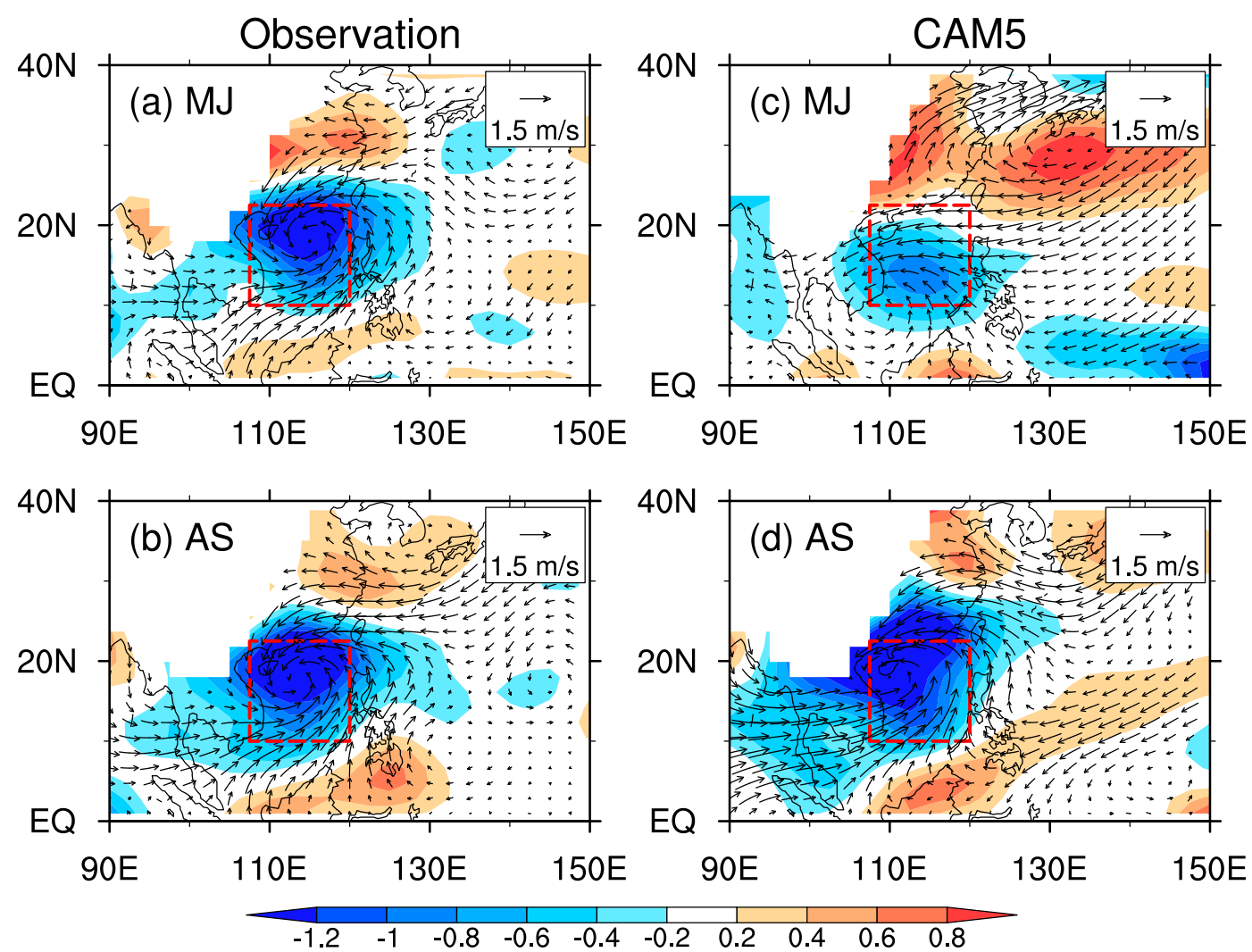

FIG. 6. Spatial distribution of composite 10-20-day observed low-level ( $925 \mathrm{hPa}$ ) horizontal divergence (shaded) and wind (vectors) in (a) MJ and (b) AS at phase 3. (c),(d) As in (a) and (b), but for model results. The shading interval is $0.2 \times 10^{-6} \mathrm{~s}^{-1}$. The SCS region is marked by the red rectangle, and areas in which the mean surface pressures less are than $925 \mathrm{hPa}$ were masked with white in each plot.

mismatch of the vorticity center and averaging latitude. As for AS (Fig. 7d), both the low-level and upper-level vorticity anomalies are simulated well in the SCS.

The QBWO convection is accompanied by strong upward motion and diabatic heating. There are strong ascending anomalies throughout the troposphere from 1000 to $100 \mathrm{hPa}$ over the SCS in both MJ and AS in observations (Figs. 7e,g), consistent with results of previous QBWO studies (e.g., Chen and Sui 2010; Yang et al. 2014). A broad maximum occupies a deep layer from 850 to $200 \mathrm{hPa}$. The CAM5 simulation, although also having strong upward motion in the whole troposphere, has strong peaks at $300 \mathrm{hPa}$ (Figs. 7f,h). In particular, in MJ, the sharp increase of vertical velocity with height above $700 \mathrm{hPa}$ indicates strong lower to midtroposphere convergence. In both observations (Figs. 7i,k) and model simulation (Figs. 7j,1), the vertical structure of the apparent heat source anomalies is similar to that of the vertical velocity in both MJ and AS. Both vertical velocity and diabatic heating in the model are stronger than in observations, consistent with the overestimated QBWO convection signals shown earlier.
To summarize, the QBWO is simulated qualitatively well by the model in both horizontal and vertical structures, although there are some biases in spatial location and intensity, especially in MJ.

\section{Vorticity budget}

To better understand the evolution of the QBWO, we further examine the budget of vorticity anomalies. Chen and Wang (2017) and Wang and Chen (2017) suggest that the meridional wind anomalies are the dominant factor influencing the evolution of the QBWO in both MJ and AS by modulating the low-level vorticity anomalies. The vorticity budget equation at the QBWO scale is given by

$$
\begin{aligned}
\frac{\partial \zeta^{\prime}}{\partial t}= & \left(-\mathbf{V}_{h} \cdot \nabla_{h} \zeta\right)^{\prime}+\left(-\omega \frac{\partial \zeta}{\partial p}\right)^{\prime}+\left(-v \frac{\partial f}{\partial y}\right)^{\prime} \\
& +[-(\zeta+f) D]^{\prime}+\left(\mathbf{k} \cdot \nabla \omega \times \frac{\partial \mathbf{V}_{h}}{\partial p}\right)^{\prime}+R,
\end{aligned}
$$

where $\zeta$ and $D$ are the relative vorticity and divergence, respectively, $f$ is the Coriolis parameter, and $\mathbf{k}$ is the unit 

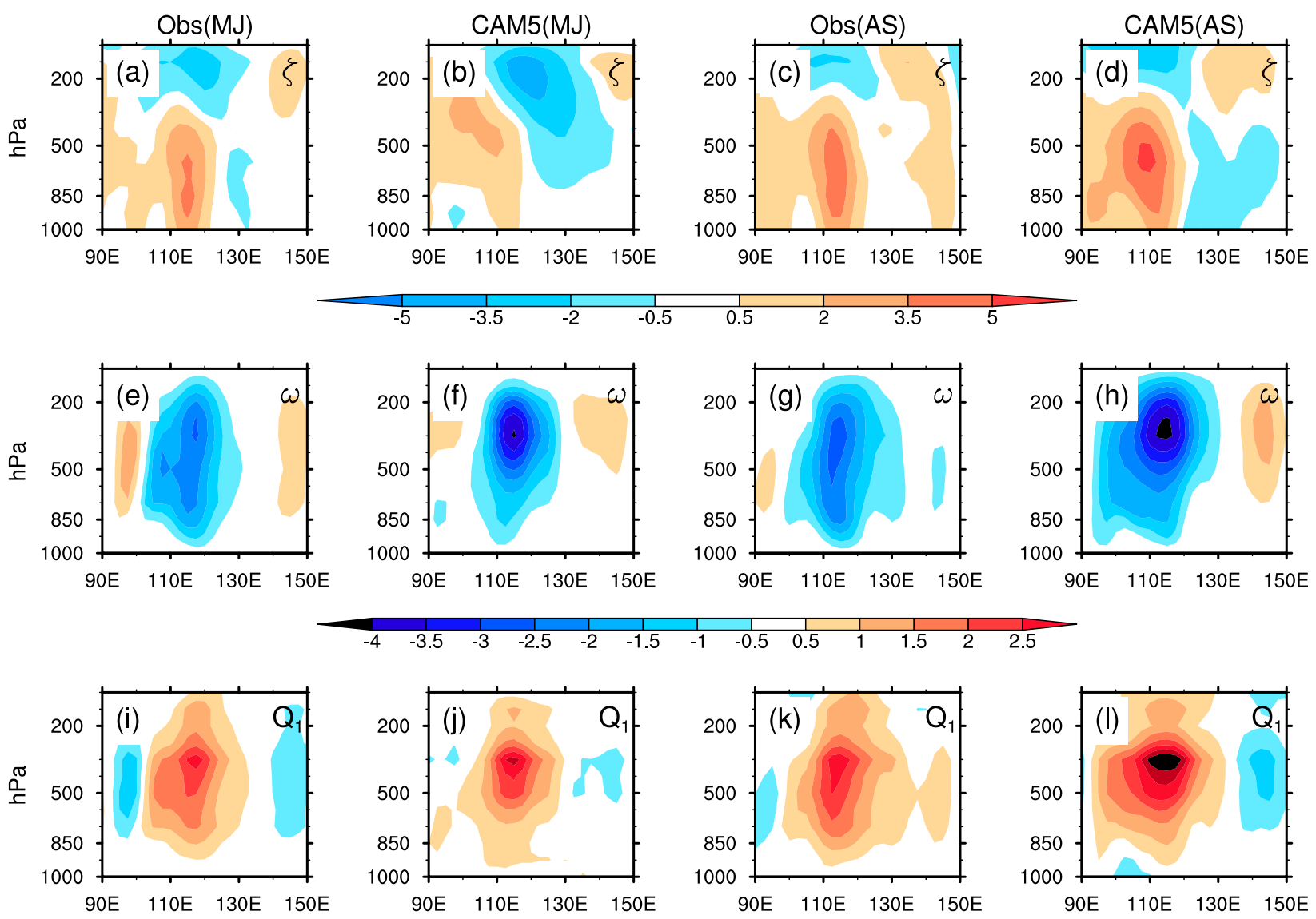

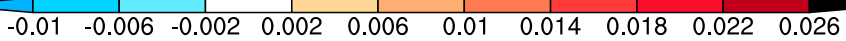

FIG. 7. Height-longitude cross section of composite 10-20-day observed (a) relative vorticity $\zeta$, (e) vertical velocity $\omega$, and (i) apparent heat source $Q_{1}$ averaged from $10^{\circ}$ to $22.5^{\circ} \mathrm{N}$ in MJ at phase 3. (b),(f),(j) As in (a), (e), and (i), but for the CAM5 simulation. (c),(d),(g),(h),(k),(l) As in (a), (b), (e),(f), (j), and (i), but for AS. The shading intervals are $1.5 \times 10^{-6} \mathrm{~s}^{-1}, 0.5 \times 10^{-2} \mathrm{~Pa} \mathrm{~s}^{-1}$, and $0.004 \mathrm{~m}^{2} \mathrm{~s}^{-3}$ for relative vorticity, vertical velocity, and apparent heat source, respectively.

vector in the vertical direction. Other symbols in the budget are the same as those defined in Eq. (1). The prime represents anomalies at the QBWO scale. The variable $\partial \zeta^{\prime} / \partial t$ on the left-hand side of Eq. (2) is the tendency of the vorticity anomalies. On the right-hand side, the first term $\left(-\mathbf{V}_{h} \cdot \nabla_{h} \zeta\right)^{\prime}$ denotes the horizontal advection of vorticity. The second term $(-\omega \partial \zeta / \partial p)^{\prime}$ is the vertical advection of vorticity. The third term $(-v \partial f / \partial y)^{\prime}$ is the horizontal advection of planetary vorticity due to Earth's rotation $(\beta$ effect $)$. The fourth $[-(\zeta+f) D]^{\prime}$ and fifth terms $\left(\mathbf{k} \cdot \nabla \omega \times \partial \mathbf{V}_{h} / \partial p\right)^{\prime}$ are the anomalies associated with the vortex tube stretching and tilting effects, respectively. The last term $R$ is the residual, including cumulus convection and other subgrid-scale transports.

Cho et al. (1983) investigated the vorticity budget in synoptic-scale tropical easterly waves in the Atlantic and found that the vorticity source due to cumulus convection largely cancels the vertical advection, stretching, and tilting effects by the large-scale circulation in the vorticity budget. If subgrid-scale transport other than that by convection is negligible, since the QBWO is of longer temporal and larger spatial scales than easterly waves, we can adopt the vorticity budget equation for the QBWO,

$$
\frac{\partial \zeta^{\prime}}{\partial t}=\left(-\mathbf{V}_{h} \cdot \nabla_{h} \zeta\right)^{\prime}+\left(-v \frac{\partial f}{\partial y}\right)^{\prime}+\frac{\sigma}{\tau}\left(\zeta_{c}^{\prime}-\zeta^{\prime}\right)
$$

where $\sigma$ and $\tau$ are the fractional cloud coverage and the mean cloud life span, respectively, $\zeta_{c}$ is the vorticity inside convective clouds, and $\sigma / \tau$ can be considered as the atmospheric recycling rate by convection (Cho 1977). See Cho et al. (1983) for details of the derivation of Eq. (3). The last term on the right-hand side of Eq. (3) represents the life cycle effect of convection on vorticity by recycling the air through convective overturning and 

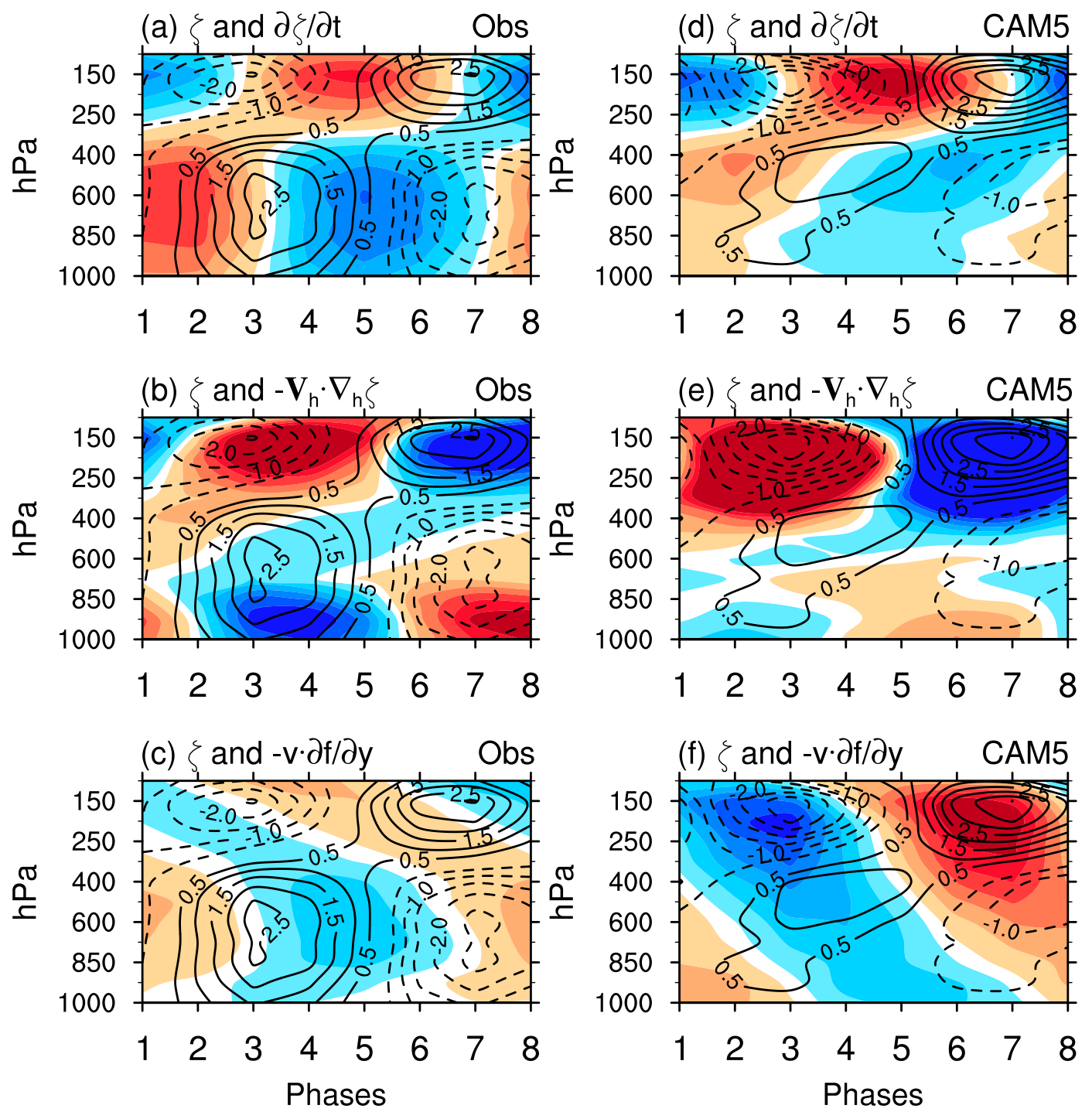

$\begin{array}{llllllllllll}-1.6 & -1.3 & -1.0 & -0.7 & -0.4 & -0.1 & 0.1 & 0.4 & 0.7 & 1.0 & 1.3 & 1.6\end{array}$

FIG. 8. Time evolution of observed 10-20-day anomalies of (a) relative vorticity tendency, (b) horizontal advection, and (c) Earth's rotation term from 1000 to $100 \mathrm{hPa}$, averaged over $10^{\circ}-22.5^{\circ} \mathrm{N}, 107.5^{\circ}-120^{\circ} \mathrm{E}$ in $\mathrm{MJ}$. The relative vorticity anomaly is superimposed for reference (contours). (d)-(f) As in (a)-(c), but for the CAM5 simulation. Contour intervals are $0.5 \times 10^{-6} \mathrm{~s}^{-1}$ for vorticity anomalies and $0.3 \times 10^{-11} \mathrm{~s}^{-2}$ for vorticity tendency, horizontal advection, and Earth's rotation effect.

replacing the environmental vorticity with vorticity inside convective clouds. However, this term cannot be computed using the reanalyses data or model output. Thus, only the horizontal advection of relative vorticity and $f$ due to Earth's rotation is examined below.

Figure 8 shows the evolution of relative vorticity, its local tendency, and the horizontal advection of relative vorticity and the $\beta$ effect, respectively, averaged over $10^{\circ}-22.5^{\circ} \mathrm{N}, 107.5^{\circ}-120^{\circ} \mathrm{E}$ for MJ. In both observations and the CAM5 simulation, in the positive QBWO convection phases, relative vorticity anomalies are positive below $300 \mathrm{hPa}$ and negative above. The negative QBWO phases show an opposite pattern. In observations, positive vorticity anomalies (contours) begin to develop in phase 2, reaching a maximum in phase 3 before decaying. By phase 5, positive anomalies have completely disappeared, followed by the development of negative anomalies. The simulated vorticity anomalies undergo similar evolution. However, there are also distinct differences between observed and simulated vorticity anomalies, with peak anomalies in phase 3 in CAM5 significantly underestimated in the lower levels, as noticed before. 
There is also a clear vertical tilt, with low-level (below $850 \mathrm{hPa}$ ) positive vorticity development leading that aloft. This, together with Fig. 7b, implies an eastward propagation of vorticity anomalies, which is quite different from the observations. Again, this is due to the contamination of the positive vorticity center north of $20^{\circ} \mathrm{N}$. The positive vorticity center south of the Tibetan Plateau is excessively strong and propagates eastward in CAM5, whereas in observations it is much weaker and propagates very slowly westward (not shown). The tendency of vorticity anomalies $\partial \zeta^{\prime} / \partial t$ on the left-hand side of Eq. (3) leads the vorticity anomalies by a quarter of cycle in both observations and the simulation (Figs. 8a,d). Similar to vorticity anomalies, the local tendency of vorticity is also smaller, especially in the lower levels, and tilted in the CAM5 simulation.

The horizontal vorticity advection $\left(-\mathbf{V}_{h} \cdot \nabla_{h} \zeta\right)^{\prime}$ in both observations and the CAM5 simulation (Figs. 8b,e) is concentrated below 850 and above $300 \mathrm{hPa}$ and is almost $180^{\circ}$ out of phase with vorticity anomalies (with a slight lag). Therefore, it acts to damp the vorticity anomalies after the latter reaches the peak, contributing to the standing oscillation of the QBWO signal. However, the amplitude in the model is underestimated below 850 and overestimated above $300 \mathrm{hPa}$. For the horizontal advection due to the $\beta$ effect $(-v \partial f / \partial y)^{\prime}$, it leads the vorticity anomalies by about a quarter of cycle in observations (Fig. 8c) below $400 \mathrm{hPa}$. As for CAM5 simulation (Fig. 8f), anomalies of the $\beta$ effect also lead vorticity anomalies below $700 \mathrm{hPa}$. However, above it, they are largely out of phase until $400 \mathrm{hPa}$ and in phase aloft with vorticity anomalies. This makes the $\beta$ effect tilt with height in the phase space. Like the horizontal advection of relative vorticity, the magnitude in the upper troposphere is much stronger in the model than in observations. Note that the difference of the $\beta$ effect between observations and model is a direct result of inaccurate simulation of the anomalous circulation (e.g., Figs. 6a,c). It can be seen that the model qualitatively simulates each contribution to the vorticity budget in the low levels (below $850 \mathrm{hPa}$ ) in $\mathrm{MJ}$, although there are large differences in the upper troposphere.

We also examined the contribution to horizontal advection of relative vorticity by the mean and anomalous fields separately (not shown). It is found that in observations, advection of mean vorticity by anomalous flow is negligible, while advection of vorticity anomalies by the mean flow is important throughout the troposphere. On the other hand, in CAM5, advection of mean vorticity by anomalous flow is important in the lower and midtroposphere, while advection of vorticity anomalies by the mean flow is important in the mid- and upper troposphere.
Figure 9 shows the phase-longitude evolution of the vorticity budget in AS. Since vorticity anomalies have a very small vertical variation in the lower half of the troposphere, individual terms in the vorticity budget are averaged from 1000 to $500 \mathrm{hPa}$ in the vertical, and from $10^{\circ}$ to $22.5^{\circ} \mathrm{N}$ in latitude. Similar to the OLR anomalies shown in Fig. 5, vorticity anomalies also propagate westward from $125^{\circ} \mathrm{E}$ in phase 1 to $110^{\circ} \mathrm{E}$ in phase 4 in observations. The CAM5 simulation shows similar propagation characteristics, except with a larger amplitude as is in OLR in Fig. 5. The local tendency [the lefthand side term of Eq. (3)] leads the vorticity anomalies by a quarter of cycle in both observations and the simulation (Figs. 9a,b), as with the situation for MJ. On the right-hand side of Eq. (3), the first term, namely, the horizontal advection of relative vorticity anomalies, shows mostly $180^{\circ}$ out of phase with vorticity anomalies except in the early phases (phases 1 and 2). Thus, it has very limited contribution to the westward propagation in both observations and CAM5 simulation (Figs. 9b,e), although it helps to reduce the vorticity anomalies locally. On the other hand, the second term, the advection due to the $\beta$ effect $(-v \partial f / \partial y)^{\prime}$, leads vorticity anomalies in both observations and simulation (Figs. 9c,f), similar to the tendency of vorticity anomalies shown in Figs. 9a and $9 \mathrm{~d}$. This indicates that the $\beta$ effect term is an important contributor to the westward propagation of the QBWO in AS.

To summarize, results from the vorticity budget at the QBWO time scale show that for MJ both the horizontal advection of relative vorticity anomalies and the advection due to the $\beta$ effect contribute to the evolution of the vorticity anomalies. For AS, the westward propagation of the QBWO is largely governed by the $\beta$ effect, although horizontal advection of relative vorticity acts to damp the vorticity anomalies locally.

Note that the cloud life cycle effect can also be important in the vorticity budget. However, since it cannot be calculated and can only be treated as a residual, we will not discuss its role in the QBWO evolution.

\section{Summary and discussion}

In this study, the QBWO features in early [May-June (MJ)] and late [August-September (AS)] summer in CAM5 are evaluated by comparing with observations. In the spatial distribution, the model successfully simulates the QBWO variances in the SCS in both MJ and AS. Major changes of the variances from MJ to AS are also well captured by the model. However, CAM5 overestimates the variance intensities in both $\mathrm{MJ}$ and AS. In the power spectrum, the signal of the QBWO is significant over the SCS in MJ in the model, but the 

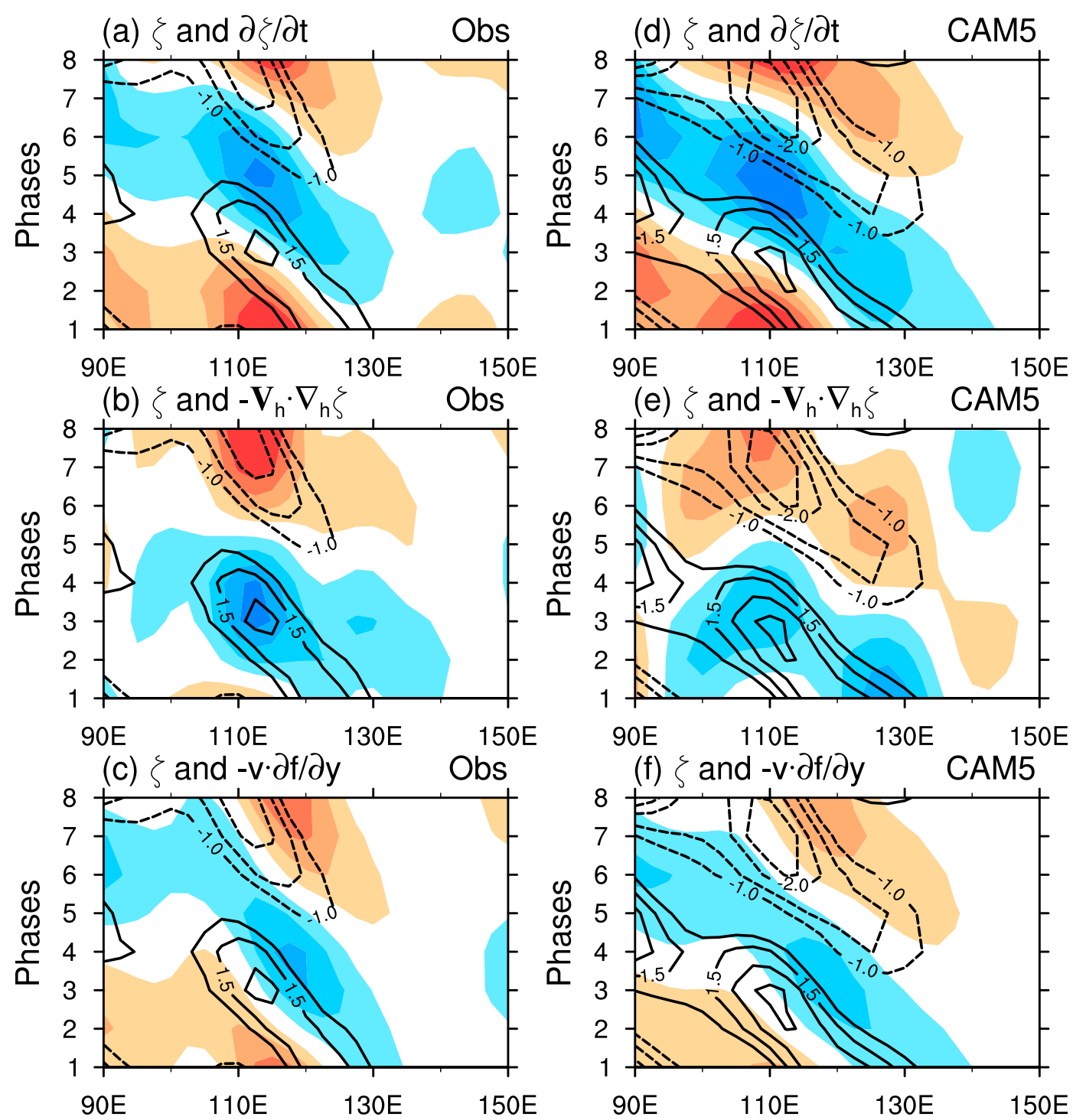

\section{$\begin{array}{llllllll}-1.1 & -0.8 & -0.5 & -0.2 & 0.2 & 0.5 & 0.8 & 1.1\end{array}$}

FIG. 9. The longitude-phase Hovmöller plots of observed 10-20-day anomalies of (a) relative vorticity tendency, (b) horizontal advection, and (c) Earth's rotation term averaged from 1000 to $500 \mathrm{hPa}$ in the vertical and from $10^{\circ}$ to $22.5^{\circ} \mathrm{N}$ in latitude, with longitude from $90^{\circ}$ to $150^{\circ} \mathrm{E}$ in AS. The relative vorticity anomaly is superimposed for reference (contours). (d)-(f) As in (a)-(c), but for the CAM5 simulation. Contour intervals are $0.5 \times 10^{-6} \mathrm{~s}^{-1}$ for vorticity anomalies and $0.3 \times 10^{-11} \mathrm{~s}^{-2}$ for vorticity tendency, horizontal advection, and Earth's rotation effect.

period is shorter than that in observations. In contrast, the signal in AS is not simulated well in the model. For the activities of the QBWO, CAM5 successfully simulates the local variation in the SCS in MJ and westward propagation in AS of the QBWO. But the intensity is overestimated significantly in both $\mathrm{MJ}$ and AS compared to observations. In terms of the spatial structure, the lowlevel convergence/divergence and cyclonic/anticyclonic circulation anomalies are qualitatively well simulated in CAM5. However, the model underestimates the convergence/divergence anomalies, and the center of cyclonic/anticyclonic circulation anomalies in the low levels in MJ is displaced to the south of the Indochina Peninsula instead of the South China Sea. The vertical structure of anomalies of relative vorticity, vertical velocity, and apparent heat source associated with the QBWO are also well captured in the model except vorticity anomalies in MJ, which are underestimated. Finally, the eddy vorticity budget is examined. Results show that the effects of horizontal advection of planetary 

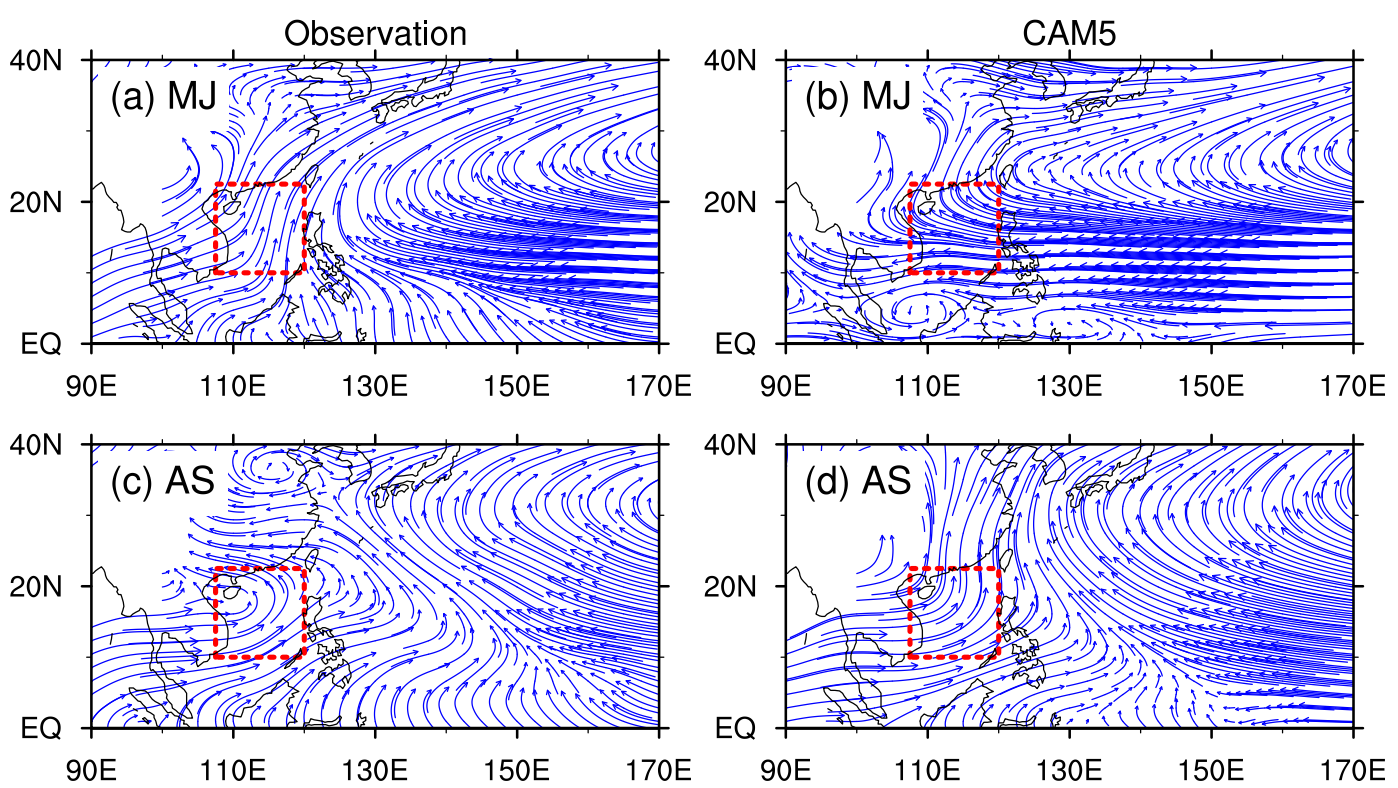

FIG. 10. Observed and modeled mean streamlines of circulation at $850 \mathrm{hPa}$ in (a),(b) MJ and (c),(d) AS. The SCS region is marked by the red rectangle in dashed lines in each plot.

vorticity associated with Earth's rotation by the meridional wind plays an important role in the westward propagation of QBWO vorticity anomalies, and CAM5 simulates this well in AS, but less so in MJ.

The underestimation of vorticity anomalies in the lower troposphere and the biases in the vorticity budget in $\mathrm{MJ}$ in the CAM5 are likely associated with the simulated mean circulation. Figure 10 shows the $850-\mathrm{hPa}$ streamlines of observations and CAM5 simulation for MJ and AS. A significant anticyclonic circulation is located east of the Philippines associated with the subtropical high $(\mathrm{SH})$ in early summer (Fig. 10a). The SCS region is located west of the $\mathrm{SH}$ ridge, with weak cyclonic or anticyclonic wind shear. Comparing with the observations, the SH ridge extends too far westward in the model (Fig. 10b), and the SCS region is dominated by anticyclonic circulation, affecting the vorticity anomalies and their budget there. For instance, vorticity advection by the mean flow, which is underestimated in the lower troposphere, is much smaller than observed because of the weak zonal gradient of vorticity and too-zonal mean flow (not shown). In AS, the subtropical high advances northeastward in observations (Fig. 10c), and the SCS region is dominated by cyclonic circulation. Convective activities in the region from $120^{\circ}$ to $150^{\circ} \mathrm{E}$ are not suppressed, allowing the westward propagation of the QBWO from east of the Philippines to the SCS. The model has a good simulation of the lowlevel circulation pattern (Fig. 10d), and the SCS is located in the mean cyclonic circulation region as observed. Previous studies have indicated the importance of the mean atmospheric circulation in QBWO initiation and development. Kikuchi and Wang (2009) suggested that the QBWO originated from moist equatorial Rossby waves modified by the climatological mean flow. Webster and Chang (1988), Kuo et al. (2001), and Chen and Sui (2010) suggested that the convergence of zonal mean flow could affect the QBWO evolution in boreal summer. The vertical transport of moisture in the QBWO could also be affected by the background surface moisture, which could change the vertical gradient of moisture (Chatterjee and Goswami 2004).

In general, the model is able to simulate the QBWO features in many aspects. However, there are also noticeable deficiencies in the simulation, such as the overestimation or underestimation in the intensity, the biases in the geographical location, and the differences in the vertical structure. The causes of these biases need further investigation in the future.

Acknowledgments. This material is based upon work supported by the National Key Research and Development Program of China Grant 2017YFA0604000, the U.S. National Science Foundation Grant AGS-1549259, and the U.S. Department of Energy, Office of Science, Biological and Environmental Research Program (BER), under Award Number DE-SC0016504. The authors thank the anonymous reviewers for their constructive comments, which have helped to improve the manuscript. The NCEPDOE Reanalyses (R-2) and OLR data are downloaded from NOAA NCEP (https://www.esrl.noaa.gov/psd/data/ gridded). The CAM5-simulation output for this study is available from the authors upon request. 


\section{REFERENCES}

Bretherton, C. S., and S. Park, 2009: A new moist turbulence parameterization in the Community Atmosphere Model. J. Climate, 22, 3422-3448, https://doi.org/10.1175/2008JCLI2556.1.

Chan, J. C. L., W. Ai, and J. Xu, 2002: Mechanisms responsible for the maintenance of the 1998 South China Sea summer monsoon. J. Meteor. Soc. Japan, 80, 1103-1113, https://doi.org/ 10.2151/jmsj.80.1103.

Chatterjee, P., and B. N. Goswami, 2004: Structure, genesis and scale selection of the tropical quasi-biweekly mode. Quart. J. Roy. Meteor. Soc., 130, 1171-1194, https://doi.org/10.1256/qj.03.133.

Chen, G., and C.-H. Sui, 2010: Characteristics and origin of quasibiweekly oscillation over the western North Pacific during boreal summer. J. Geophys. Res., 115, D14113, https://doi.org/ 10.1029/2009JD013389.

, and X. Wang, 2017: Effect of the westward-propagating zonal wind anomaly on the initial development of quasi-biweekly oscillation over the South China Sea during early summer. Atmos. Oceanic Sci. Lett., 10, 89-95, https://doi.org/10.1080/ 16742834.2017.1243002.

Chen, T.-C., and J.-M. Chen, 1995: An observational study of the South China Sea monsoon during the 1979 summer: Onset and life cycle. Mon. Wea. Rev., 123, 2295-2318, https://doi.org/ 10.1175/1520-0493(1995)123<2295:AOSOTS > 2.0.CO;2.

- M.-C. Yen, and S.-P. Weng, 2000: Interaction between the summer monsoons in East Asia and the South China Sea: Intraseasonal monsoon modes. J. Atmos. Sci., 57, 1373-1392, https://doi.org/10.1175/1520-0469(2000)057<1373: IBTSMI > 2.0.CO;2.

Cho, H.-R., 1977: Contribution of cumulus cloud life-cycle effects to the large-scale heat and moisture budget equations. J. Atmos. Sci., 34, 87-97, https://doi.org/10.1175/1520-0469(1977)034<0087: COCCLC $>2.0$. CO;2.

— M. A. Jenkins, and J. Boyd, 1983: A first order vorticity equation for tropical easterly waves. J. Atmos. Sci., 40, 958-968, https:// doi.org/10.1175/1520-0469(1983)040<0958:AFOVEF>2.0.CO;2.

Duchon, C. E., 1979: Lanczos filtering in one and two dimensions. J. Appl. Meteor., 18, 1016-1022, https://doi.org/10.1175/ 1520-0450(1979)018<1016:LFIOAT > 2.0.CO;2.

Fukutomi, Y., and T. Yasunari, 1999: 10-25 day intraseasonal variations of convection and circulation over East Asia and western North Pacific during early summer. J. Meteor. Soc. Japan, 77, 753-769, https://doi.org/10.2151/jmsj1965.77.3_753.

Hu, W., A. Duan, and B. He, 2017: Evaluation of intra-seasonal oscillation simulations in IPCC AR5 coupled GCMs associated with the Asian summer monsoon. Int. J. Climatol., 37, 476-496, https://doi.org/10.1002/joc.5016.

Iacono, M. J., E. J. Mlawer, S. A. Clough, and J.-J. Morcrette, 2000: Impact of an improved longwave radiation model, RRTM, on the energy budget and thermodynamic properties of the NCAR Community Climate Model, CCM3. J. Geophys. Res., 105, 14 873-14 890, https://doi.org/10.1029/2000JD900091.

Jia, X., and S. Yang, 2013: Impact of the quasi-biweekly oscillation over the western North Pacific on East Asian subtropical monsoon during early summer. J. Geophys. Res. Atmos., 118, 4421-4434, https://doi.org/10.1002/jgrd.50422.

Kanamitsu, M., W. Ebisuzaki, J. Woollen, S.-K. Yang, J. J. Hnilo, M. Fiorino, and G. L. Potter, 2002: NCEP-DOE AMIP-II Reanalysis (R-2). Bull. Amer. Meteor. Soc., 83, 1631-1643, https://doi.org/10.1175/BAMS-83-11-1631.

Kang, I.-S., and Coauthors, 2002: Intercomparison of the climatological variations of Asian summer monsoon precipitation simulated by 10 GCMs. Climate Dyn., 19, 383-395, https:// doi.org/10.1007/s00382-002-0245-9.

Kemball-Cook, S., and B. Wang, 2001: Equatorial waves and air-sea interaction in the boreal summer intraseasonal oscillation. J. Climate, 14, 2923-2942, https://doi.org/10.1175/1520-0442(2001)014<2923: EWAASI $>2.0 . \mathrm{CO} ; 2$.

Keshavamurty, R. N., 1972: On the vertical tilt of monsoon disturbances. J. Atmos. Sci., 29, 993-995, https://doi.org/10.1175/ 1520-0469(1972)029<0993:OTVTOM >2.0.CO;2.

Kikuchi, K., and B. Wang, 2009: Global perspective of the quasibiweekly oscillation. J. Climate, 22, 1340-1359, https://doi.org/ 10.1175/2008JCLI2368.1.

Ko, K.-C., and D. G. Vincent, 1995: A composite study of the quasiperiodic subtropical wind maxima over the South Pacific during November 1984-April 1985. J. Climate, 8, 579-588, https://doi.org/ 10.1175/1520-0442(1995)008<0579:ACSOTQ>2.0.CO;2.

— , and — 1996: Behavior of one to two week summertime subtropical wind maxima over the South Pacific during ENSO cycle. J. Climate, 9, 5-16, https://doi.org/10.1175/1520-0442 (1996) 009<0005:BOOTTW $>2.0 . C O ; 2$.

Krishnamurti, T. N., and H. N. Bhalme, 1976: Oscillations of a monsoon system. Part I. Observational aspects. J. Atmos. Sci., 33, 1937-1954, https://doi.org/10.1175/1520-0469(1976)033<1937: OOAMSP $>2.0 . \mathrm{CO} ; 2$.

— , and P. Ardanuy, 1980: The 10 to 20-day westward propagating mode and "Breaks in the Monsoons." Tellus, 32, 15-26, https://doi.org/10.3402/tellusa.v32i1.10476.

Kuo, H.-C., J.-H. Chen, R. T. Williams, and C.-P. Chang, 2001: Rossby waves in zonally opposing mean flow: Behavior in northwest Pacific summer monsoon. J. Atmos. Sci., 58, 1035-1050, https://doi.org/10.1175/1520-0469(2001)058<1035: RWIZOM $>2.0 . C O ; 2$.

Li, C., T. Li, A. Lin, D. Gu, and B. Zheng, 2015: Relationship between summer rainfall anomalies and sub-seasonal oscillations in South China. Climate Dyn., 44, 423-439, https://doi.org/ 10.1007/s00382-014-2172-y.

Li, R. C. Y., and W. Zhou, 2013: Modulation of western North Pacific tropical cyclone activity by the ISO. Part I: Genesis and intensity. J. Climate, 26, 2904-2918, https://doi.org/10.1175/ JCLI-D-12-00210.1.

Li, T., and B. Wang, 2005: A review on the western North Pacific monsoon: Synoptic-to-interannual variabilities. Terr. Atmos. Oceanic Sci., 16, 285-314, https://doi.org/10.3319/ TAO.2005.16.2.285(A).

Liang, J., L. Wu, X. Ge, and C.-C. Wu, 2011: Monsoonal influence on typhoon Morakot (2009). Part II: Numerical study. J. Atmos. Sci., 68, 2222-2235, https://doi.org/10.1175/2011JAS3731.1.

Liebmann, B., 1996: Description of a complete (interpolated) outgoing longwave radiation dataset. Bull. Amer. Meteor. Soc., 77, 1275-1277.

Lin, J.-L., K. M. Weickman, G. N. Kiladis, B. E. Mapes, S. D. Schubert, M. J. Suarez, J. T. Bacmeister, and M.-I. Lee, 2008: Subseasonal variability associated with Asian summer monsoon simulated by 14 IPCC AR4 coupled GCMs. J. Climate, 21, 4541-4567, https://doi.org/10.1175/2008JCLI1816.1.

Liu, H.-B., J. Yang, D.-L. Zhang, and B. Wang, 2014: Roles of synoptic to quasi-biweekly disturbances in generating the summer 2003 heavy rainfall in East China. Mon. Wea. Rev., 142, 886-904, https://doi.org/10.1175/MWR-D-13-00055.1.

Madden, R. A., and P. R. Julian, 1971: Detection of a 40-50-day oscillation in the zonal wind in the tropical Pacific. J. Atmos. Sci., 28, 702-708, https://doi.org/10.1175/1520-0469(1971)028<0702: DOADOI $>2.0 . \mathrm{CO} ; 2$ 
, and — 1972: Description of global-scale circulation cells in the tropics with a 40-50-day period. J. Atmos. Sci., 29, 1109-1123, https://doi.org/10.1175/1520-0469(1972)029<1109: DOGSCC $>2.0 . \mathrm{CO} ; 2$.

Mao, J., and J. C. L. Chan, 2005: Intraseasonal variability of the South China Sea summer monsoon. J. Climate, 18, 2388-2402, https://doi.org/10.1175/JCLI3395.1.

- and G. Wu, 2006: Intraseasonal variations of the Yangtze rainfall and its related atmospheric circulation features during the 1991 summer. Climate Dyn., 27, 815-830, https://doi.org/ 10.1007/s00382-006-0164-2.

Mlawer, E. J., S. J. Taubman, P. D. Brown, M. J. Iacono, and S. A. Clough, 1997: Radiative transfer for inhomogeneous atmospheres: RRTM, a validated correlated-k model for the longwave. J. Geophys. Res., 102, 16 663-16 682, https://doi.org/ 10.1029/97JD00237.

Morrison, H., and A. Gettelman, 2008: A new two-moment bulk stratiform cloud microphysics scheme in the Community Atmosphere Model, version 3 (CAM3). Part I: Description and numerical tests. J. Climate, 21, 3642-3659, https://doi.org/ 10.1175/2008JCLI2105.1.

Murakami, M., 1976: Analysis of summer monsoon fluctuations over India. J. Meteor. Soc. Japan, 54, 15-31, https://doi.org/ 10.2151/jmsj1965.54.1_15.

Murakami, T., and M. Frydrych, 1974: On the preferred period of upper wind fluctuations during the summer monsoon. J. Atmos. Sci, 31, 1549-1555, https://doi.org/10.1175/1520-0469(1974)031<1549: OTPPOU $>2.0 . \mathrm{CO} 2$.

Neale, R. B., J. H. Richter, and M. Jochum, 2008: The impact of convection on ENSO: From a delayed oscillator to a series of events. J. Climate, 21, 5904-5924, https://doi.org/10.1175/2008JCLI2244.1. , and Coauthors, 2012: Description of the NCAR Community Atmosphere Model (CAM 5.0). NCAR Tech. Note NCAR/ TN-486+STR, 274 pp., www.cesm.ucar.edu/models/cesm1.0/ cam/docs/description/cam5_desc.pdf.

Park, S., and C. S. Bretherton, 2009: The University of Washington shallow convection and moist turbulence schemes and their impact on climate simulations with the Community Atmosphere Model. J. Climate, 22, 3449-3469, https://doi.org/ 10.1175/2008JCLI2557.1.

Sabeerali, C. T., A. R. Dandi, A. Dhakate, K. Salunke, S. Mahapatra, and S. A. Rao, 2013: Simulation of boreal summer intraseasonal oscillations in the latest CMIP5 coupled GCMs. J. Geophys. Res. Atmos., 118, 4401-4420, https://doi.org/10.1002/jgrd.50403.

Waliser, D. E., and Coauthors, 2003: AGCM simulations of intraseasonal variability associated with the Asian summer monsoon. Climate Dyn., 21, 423-446, https://doi.org/10.1007/ s00382-003-0337-1.

Wang, B., 1988: Dynamics of tropical low-frequency waves: An analysis of the moist Kelvin wave. J. Atmos. Sci., 45, 2051-2065, https://doi.org/10.1175/1520-0469(1988)045<2051: DOTLFW $>2.0 . \mathrm{CO} ; 2$.

— dynamics in the development of a tropical intraseasonal system. J. Atmos. Sci., 51, 1386-1400, https://doi.org/10.1175/ 1520-0469(1994)051<1386:CIWBLD>2.0.CO;2.

_, F. Huang, Z. Wu, J. Yang, X. Fu, and K. Kikuchi, 2009: Multiscale climate variability of the South China Sea monsoon: A review. Dyn. Atmos. Oceans, 47, 15-37, https://doi.org/ 10.1016/j.dynatmoce.2008.09.004.

Wang, X., and G. Chen, 2017: Quasi-biweekly oscillation over the South China Sea in late summer: Propagation dynamics and energetics. J. Climate, 30, 4103-4112, https://doi.org/10.1175/ JCLI-D-16-0533.1.

_ - _ , and R. Huang, 2016: Different characteristics of the quasi-biweekly oscillation over the South China Sea in two boreal summer stages. Theor. Appl. Climatol., 126, 1-13, https://doi.org/10.1007/s00704-015-1550-7.

Webster, P. J., and H.-R. Chang, 1988: Energy accumulation and emanation regions at low latitudes: Impacts of a zonally varying basic state. J. Atmos. Sci., 45, 803-829, https://doi.org/ 10.1175/1520-0469(1988)045<0803:EEAAER>2.0.CO;2.

Wu, L., J. Liang, and C.-C. Wu, 2011: Monsoonal influence on Typhoon Morakot (2009). Part I: Observational analysis. J. Atmos. Sci., 68, 2208-2221, https://doi.org/10.1175/ 2011JAS3730.1.

Xu, Z., T. Li, and K. Fan, 2017: The weakened intensity of atmospheric quasi-biweekly oscillation over the western North Pacific during late summer around the late 1990s. J. Climate, 30, 9807-9826, https://doi.org/10.1175/JCLI-D-16-0759.1.

Yang, J., B. Wang, B. Wang, and Q. Bao, 2010: Biweekly and 2130-day variations of the subtropical summer monsoon rainfall over the lower reach of the Yangtze River basin. J. Climate, 23, 1146-1159, https://doi.org/10.1175/2009JCLI3005.1.

—, Q. Bao, B. Wang, D.-Y. Gong, H. He, and M.-N. Gao, 2014 Distinct quasi-biweekly features of the subtropical East Asian monsoon during early and late summers. Climate Dyn., $\mathbf{4 2}$, 1469-1486, https://doi.org/10.1007/s00382-013-1728-6.

Zhang, G. J., and N. A. McFarlane, 1995: Sensitivity of climate simulations to the parameterization of cumulus convection in the $\mathrm{Ca}$ nadian Climate Centre general circulation model. Atmos.-Ocean, 33, 407-446, https://doi.org/10.1080/07055900.1995.9649539. 